\title{
Study on the Composition of Regional Scientific and Technological Innovative Competence and its Upgrade Mechanism
}

\author{
Yingjuan Feng (Corresponding author) \\ School of Economics and Management, Changchun University of Science and Technology \\ 7989 Weixing Road, Changchun 130022, China \\ Tel: 86-431-8628-7978Ｅ-mail: blessyandm@163.com \\ Yan Wang (Corresponding author) \\ School of Economics and Management, Changchun University of Science and Technology \\ 7989 Weixing Road, Changchun 130022, China \\ Tel: 86-431-8521-7930Ｅ-mail: wangyan@163.com
}

\begin{abstract}
At present, the world economy is shifting to the model of knowledge-based economy, knowledge and technology to economic growth has greatly exceeded the sum of the contribution of capital, labor and natural resources and become the most important economic factors, economic growth rely on scientific and technological progress than before, scientific and technological innovation is more important than ever before, it is becoming the main causes and the most direct driving force of a region or country's economic growth and development. This paper starts from the meaning of regional scientific and technological innovative competence; analyze the composition and upgrade mechanism of regional scientific and technological innovative competence.
\end{abstract}

Keywords: Regional scientific and technological innovative competence, Composition, Upgrades mechanism

\section{Introduction}

Since the Austrian-American economist - Schumpeter put forward the concept what is a kind of innovative changes in the production function for the first time in "Economic Development Theory" which published in 1912, and particularly emphasizes on" economic changes, such as reduced costs, the economic balance broken, brutal competition and the economic cycle itself, should be mainly attributable to Innovation ", henceforth the innovation has been the hotspot of international study, but in different countries, different periods of time, it has been given to the different characteristics.

\section{Meaning of Regional scientific and technological innovation}

Regional scientific and technological innovation meanly that in the given region, under the regional context, science, technology, education, economy and other factors shape the incorporate development mechanism, is the regional system whose main body is enterprise and include local government, education and scientific research units, intermediary organizations. It relies on the strength of regional science and technology innovation, uses resources of regional scientific and technological innovation effectively, coordinates the inter-regional cooperation in science and technology and competition, and achieves efficient allocation of scientific and technological innovation resources (personnel, knowledge, inputs) and the structural optimization, promotes the extensive development of regional scientific and technological innovation and the application, promotion and popularization of innovative product. And then create and develop the competitive advantage to ensure regional economic development. Regional scientific and technological innovation system is the network which regional science and technology organizations, universities, business interact and develop together. This innovative system has the main features of the system, but is open. The System bear the task of putting the high-tech science and technology into the development of regional economic variables, promoting the regional industrial structure modernization and optimization, so as to ensure regional economic and social sustainable development.

From the practice of each regional economic development, the regional competitive ability especially the strength of sustainable competitiveness mainly depends on its scientific and technological ability. 


\section{Composing of Regional Scientific and Technological Innovative Competence}

From the successful experience of developed countries, generally the regional scientific and technological innovative competence should have 8 parts, such as the capability of independent innovation, comprehensive utilization of extra-territorial technology, supply of the innovative system, open up new markets, management innovation, development of new resources, coordination and advanced thinking ability.

\subsection{Capability of Independent Innovation}

To understand independent innovation, first of all, is a direction. It emphasizes that we need innovative thinking, based on our own strength, innovation as much as possible. At the same time, do not rule out studying others.

Innovation can be divided into 3 categories: (1) integration independent innovation, it is the organic integration of a variety of related technologies to form products and industries with market competitive; (2) introduce or imitate innovation, based on the introduction of foreign advanced technology, to promote positively digestion, absorption and re-innovation; (3) originality independent innovation, that is, through their own new technology research and invention, and developed a new or next generation products. Their Common ground is the unique core technology which has the intellectual property and on the basis to form the value of new products. The capability of independent innovation is the region (enterprises) use effectively innovative resources, establish a new technology platform or change the core technology and achieve independent intellectual property, so that the region will continue to enhance its core competitiveness ability and obtain sustainable competitive advantage in the market competition, in the process of technological innovation to express organic colligation of various ability.

\subsection{Capacity of Comprehensive Utilization of Extra-territorial Technology}

Capacity of comprehensive utilization of extra-territorial technology mainly refers to the extraterritorial appropriate technology. The so-called appropriate technology, not high-tech necessarily, as long as suiting the stage of regional economic development, to make the region access to sustainable development capacity through using and popularization of technology.

Capacity of comprehensive utilization of extra-territorial technology indicates that the region under circumstances of lacking originality as individual, and attract the extraterritorial appropriate technology for its own using, the focus is on the basis of digestion and absorption, improvement and innovation or change the core technology to produce new products. However, because "partial" or "minor" changes, it is commonly difficult to apply to the patents and not have independent intellectual property rights. Comprehensive utilization of extra-territorial technology is a better choice, such as the backward areas implement "catch-up strategy".

\subsection{Capacity of the supply of innovative system}

Regional scientific and technological innovation required system collaboration of the whole society and can not be separated from regulation and control of system norms and policy guidance and support of government, such as a series of taxation, finance, industrial technology, personnel incentives. If no such systems and policies, technological innovations will no step. Mechanism is as shown in Figure 1.

\subsection{Capacity to Open Up New Markets}

Explicit manifestations of capacity of regional scientific and technological innovation are able to produce the high-tech, high value-added products which can meet market demand and consumers agree to accept, and then through market exchange to successfully realize the value compensation. And Japan's "low-volume, diversification" Toyota production model has been exceed America's "high-volume, low diversification" the new winter system, and its drawbacks are that the production scale is small and production cost is high. Therefore, opening up new markets and expanding market size are imperative to obtain economies of scale.

\subsection{Capacity of Management Innovation}

With the advent of a knowledge-based economy, science and technology change with each passing day, market competition is growing, complexity and difficulty of regional scientific and technological innovation is greater, so whether if can the government management system innovates with the time from the government-funded, creation purchase, nail down orientation, the patent system, tax incentives, direct investment, and integration innovation, continue to management innovation and strengthen policies to encourage scientific and technological innovation are particularly important.

\subsection{Capacity to develop new resources}

Resources are the basis for regional economic development, and agelong supply of resources is the basis for sustainable development of the region. Throughout the regional resources system, the vast majority of resources (in particular, non-renewable mineral resources) lack flexibility in supply in the near future. Therefore, continue to develop new resources to provide sustainable supply of resources to promote regional sustainable economic development is one of 
main mission of regional scientific and technological innovation and also a main component of regional scientific and technological innovation competence.

\subsection{Capacity of advanced thinking}

In economic development, we say "the idea is everything", and in science and technology innovation, we believe that "advanced thinking decides everything." Since the difficulty of original innovation: firstly, rely on the accumulation of knowledge; secondly, rely on inspiration of a handful genius. Where does inspiration come from? In fact, it comes from the advanced thinking ability of scientists.

Scientists only have the advanced thinking ability can sudden blaze inspiration and to create original innovative, to produce a new product; scientists only have the advanced thinking ability to be possible to set a variety of existing technologies form integrated innovation, and developed new improved products; only have the advanced thinking ability can enhance its digestion and absorption capacity of imported technology, and on this basis to form introduction innovation, access to their own intellectual property rights.

If government does not have an advanced thinking ability, will not be able to formulate scientific strategies for regional economic development, but also impossible to provide system supply in favor of scientific and technological innovation, would be impossible to upgrade the capacity of regional scientific and technological innovation.

\subsection{Capacity of Coordination}

Regions itself is a complex economic and social system, inside and outside of the region have a variety of economic and interest actors, in the course of economic operation, if let the market mechanism to allocate freely, there would exist the case of market failure, such as externalities and public goods, especially in science and technology innovation system to promote regional economic development. In nature, science and technology is a kind of public goods of strong spillover effects, "free-rider" phenomenon is more likely appear; the external effects of scientific and technological achievements are also great and positive; $\mathrm{R} \& \mathrm{D}$ investment is great, but results and earnings are uncertainty, so it is a high-risk, high investment activity, only one or a few enterprises can not be completed. Therefore, the Government of the Organization Coordination ability is very important and necessary.

\section{Upgrade Mechanism of Regional Scientific and technological innovation Competence}

From economic development practice of developed countries such as the US and Japan, to keep the competitiveness of the regional economy than ever, using regional scientific and technological innovation to promote regional economic development. Therefore, we must form upgrade mechanism of regional scientific and technological innovation capacity. Learning from international successful experience, generally we should do the following four areas:

\subsection{Construct the Regional Scientific and Technological Innovation System Which Main body is enterprises}

Looking from outside mechanism, we must intensify system reforms; to achieve separation of political from capital, separation of government from enterprises, rely on preferential policies, legal protection and market incentives to turn enterprises into the investors, beneficiary, risk takers, main body of research and development, main body of decision-making of technological innovation,; analysis from internal mechanisms, we must implement modern enterprise system, through system innovation, such as property rights system, incentive systems, organizational systems, to promote technological innovation; through capital market to achieve enterprises' strategic restructuring and the survival of the fittest, accelerate the technological transformation of traditional industries, establish the benefits and risk-driven mechanisms of technological innovation, promote large and medium-sized enterprises to establish a sound scientific research and development institutions, as soon as possible to form a number of large-scale enterprises group with independent innovation ability and to match multi-national corporations; change the approach that state-owned enterprise managers appointed by the superior, and gradually establish and perfect the market selection and wash out mechanism of enterprise managers, establish an effective entrepreneurship motivation, discipline and supervision mechanism, bring into play fully the entrepreneurs' soul and core role in technological innovation.

\subsection{Construct the Experts Community of Regional Economic Development}

In the era of knowledge economy, knowledge is the first resources or key resources of regional economic development, and people are carriers of knowledge who use knowledge to innovate and change the world; we say "the idea determines everything, the idea is wrong and then all are wrong", the idea refers to that of government leaders and entrepreneurs; even if the region has more scientific and technological resources, if not to be organized reasonably and optimize the configuration, it can not form a strong scientific and technological innovation capacity of region to promote regional economic development, thus need the outstanding intellectual leader in knowledge fields. Therefore, in order to enhance the capacity of regional scientific and technological innovation, we must establish experts community of regional economic development. 


\subsection{Construct a harmony and unification management system}

The key to harmony and unification management system is that government should strengthen communication and coordination. (1) Internal coordination problem of government departments. Government would understand more about the factors which affects capabilities of regional scientific and technological innovation and it's role in their own scientific and technological innovation system. Summarize the successful experience of the relevant bodies and generalize them at other agencies, utilize new or existing forum, among government, enterprises, colleges and research institutions to discuss the common problems to influence on regional scientific and technological innovation system development; (2) the problem of co-ordination between business and government. Try to recognize explicitly that there are partnership and common benefits between the support of regional science and technology innovation system of state-owned enterprises and the private sector, to enhance their mutual complementarily. At present, more and more activities of state-owned enterprises run out that of private sector. Therefore, it is necessary to strengthen the coordination between them so that they can only work together for regional technological innovation system to make their own contribution; (3) to strengthen regional people's understanding of scientific and technological innovation system. Try to let people know the importance of innovative activity, as well as the means by which the people to support innovation, improve the well-known degree of the award in the technological development field; (4) to reinforce inter-regional and international cooperation, to strengthen recognition of the excellent Technology Center to encourage inter -regional and even cross-border cooperation in science and technology.

\subsection{Construct the perfect investment and financing system of regional scientific and technological innovation}

The upgrade of regional scientific and technological innovation capability depends on a great deal of R \& D inputs, no abundant risk capital, same as the car does not oil, the whole system of regional scientific and technological innovation are not functioning. And rely on financial investment only, capacity is limited, or there would be Chinese "Tsukuba" situation; if only rely on corporate investment, because the risks may be difficult to do so. Therefore, must be guided by government policies favoring to form a perfect, including government, financial institutions and non-governmental organizations, diversified, market-oriented, new-style risk investment and financing system.

\section{Conclusion}

In a word, each region should base on understanding of composition of regional scientific and technological innovative competence and its upgrade mechanism, combing with its own practice of regional economic development, to constitute the countermeasures to upgrade the competence.

\section{References}

Wang, Delu. (2000). Grow up of Region- Studies on Regional Innovation Theory and Cases. Beijing: Aviation Industry Press.

Wang, yan. (2007). Theoretical Research on Independent Innovation for Regional Economic Development [D]. PhD thesis.

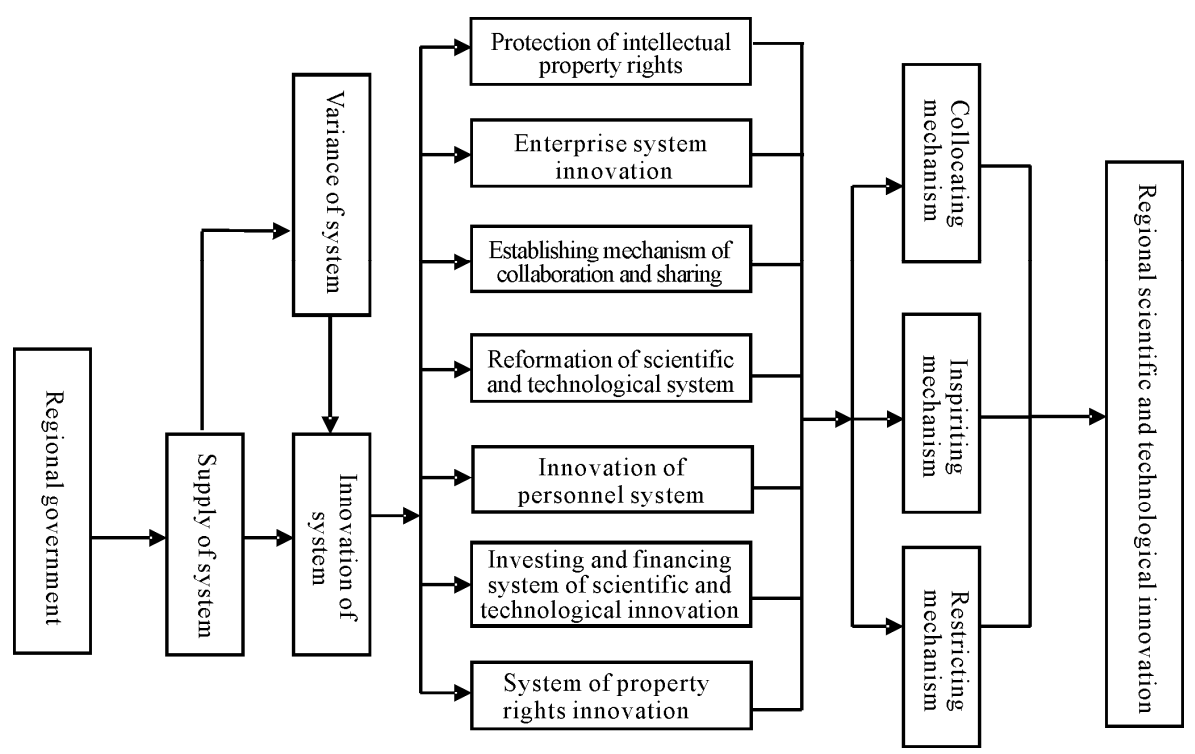

Figure 1. Supply of system of Regional scientific and technological innovation 